\title{
Addressing Social Innovation in the Malaysian Knowledge Transfer Program: Gaining a Preliminary Insight
}

\author{
Muhamad Nizam Jali ${ }^{1}$, Zakaria Abas ${ }^{2}$, Ahmad Shabudin Ariffin ${ }^{3}$ \\ ${ }^{I}$ (College of Business/ Universiti Utara Malaysia, Malaysia) \\ ${ }^{2}$ (College of Business/ Universiti Utara Malaysia, Malaysia) \\ ${ }_{3}^{3}$ (College of Business/ Universiti Utara Malaysia, Malaysia)
}

\begin{abstract}
Only recently, developed countries such as the US, UK and some wealthy European Union countries have been chanting out social innovation as their new innovation outcome strategy. This is due to the fact that, the contribution of social innovation is said to be much greater and portrayed significant benefits as compared to technological innovation per se. Social innovation gives concurrent benefits towards social, economic and technological aspects, whereas technological innovation limitedly contribute to merely fulfilling private needs. Various developed countries staggered on social innovation as their new innovation outcome strategy through knowledge transfer partnership between private, academic and community institution, whereby new superior knowledge resource is created through the processes of creation, transfer and application of knowledge within the partnership ecosystem. This new superior knowledge is then embedded into products, processes and services which in turn produced highly innovative products, processes and services that contribute towards social, economic and technological payoffs. In tandem with the above thought, this paper promotes the concept of social innovation within the context of Malaysian Knowledge Transfer Partnership (KTP) projects by addressing it through qualitative approach of inquiry. This paper provides an insight and suggests that so far, social innovation is quite a new theme for various actors involves in Malaysian KTP projects and technological innovation is still very much focused on the KTP projects outcome. Hence, a better understanding on social innovation as a new innovation outcome strategy must be internalized by all actors involved in the Malaysian KTP projects. It is evidence that, various actors within the Malaysian KTP projects have diverse objectives, interest and priorities towards their involvement in the Malaysian KTP projects. The presence of high bureaucracy practices, business disclosures issues, innovation requirements issues, understanding and commitment issues and financial constraints are the main challenges faced by various actors involves in the Malaysian KTP projects. Thus, having recognized all the said elements above and prioritizing further with careful coordination and organization, it is hope that the Malaysian KTP projects could be successfully enshrines social innovation as a new innovation outcome strategy that perhaps may give a massive contribution towards facilitating the aspiration of Eleventh Malaysia Plan (RMK-11;2016-2020) with the theme "anchoring growth on people" in lights of fulfilling Malaysia to achieve a high income country status
\end{abstract}

Keywords: Knowledge resource, KTP partnership, Social innovation

\section{Introduction}

In recent years, the issues of poor social health, poor standard of living, poor education systems, public income inequality, massive unemployment and poor economic growth is being identified as the most crucial and long-standing social and economic problems that face by many develops and developing nations worldwide. With regards to the issues mentioned above, innovation is the notion that being regarded as the vital solution in improving social well-being and also promoting economic growth [1]. However, the presence paradigm of innovation outcome that refers to technological innovation is perhaps no longer sufficient in dealing with the aforementioned issues [2]. To elaborate further, [3] stressed that, technological innovation is very much incline and focus towards private maximization that somehow gives huge advantage to the commercial driven innovation. Furthermore, according to [4], when technological innovation is adopted within a particular organization, the aspect of "social well-being" is somewhat being undervalue due to its nature that specifically focus on satisfying private markets. Hence, there is a consensus worldwide on the urgency to find a new paradigm of innovation that can become a better solution in order to solve the pressing social and economic and technological issues above in a concurrent way [5].

Given that, social innovation has emerged as a new and outstanding solution that offers various concern stakeholders a better outcome in dealing with the social, economic and technological issues [6]. The contribution of social innovation is said encompasses social, economic and technological aspects [7], [8] that includes the outcomes of better living condition of people's life, better environmental condition, better education, better human development, increase in economic growth, increase employment opportunity and also contributes towards profit maximization and private needs [9]. As a result, social innovation is attracting the 
interest and attention of government, academia, private and community institutions worldwide [6]. Continuously, with the recognition of social innovation as the driver of change and sustainable development within social, economic and technological environment, social innovation has secured an important place within many nations' core policies worldwide. According to [10], the inclusion and incorporation of social innovation into the main stream of national economic policy initiatives started within the develop countries among other in the UK, USA and many European countries only recently. As evidence, The European Union countries among others, United Kingdom, The Netherlands, France, Belgium and Germany had developed various policy initiatives to stress the urgency and the importance of adopting social innovation as an innovation outcome towards their public and private organizations innovation strategy. Thus, the importance of social innovation had been addressed accordingly in the European Union 2020 policy strategy, The UK social innovation impacts investment policy 2013, The UK Big Society Capital 2012, Dortmund, Brussels position paper on workplace innovation 2012, and also European foundation for improvement of living and working condition 2012 [9]. In more recent policy initiatives, [11] develops a comprehensive guideline report on social innovation. This report highlights that social innovation is of great potential in addressing complex social, economic and technological problems where other innovation outcomes have been ineffective [2,9]. Furthermore, the guideline report by [11] emphasis that social innovation is the flagship program and act as a problem solver mechanism in addressing the issues of unemployment, poor education, poverty reduction and resource inefficiency that all European Union members' countries must be able to overcome by the year 2020. According to [12], the success of aforementioned social innovation policy initiatives by various European Union countries members is largely dependent on the vibrant partnership between universities, business and community entities and government supports that creates core knowledge resource serving local society and economy.

According to [13], social innovation as an outcome objective of partnership between public and private entities in various European countries had contributes towards achieving a relatively higher percentage of citizen's employments, higher improvement on citizen's health, advances in education systems and also enhances economic growth within their respective country. Furthermore, according to [6], the US as the prominent source of social innovation also yield a remarkable return in terms of social and economic benefits i.e. job creations, public educations, citizen welfare, economic value and commercial success; with the implementation of social innovation within their policy initiatives. Continuously, the increasing public interest and awareness on social innovation contribution had put alliance partners such as university, industry and community partnership in a forefront of attention by the governments worldwide in achieving social innovation [14]. Academia represents a potential important source of superior knowledge resource that is valuable for new innovation that can be embedded into products, processes and services in order to overcome social and economic problems [15]. Therefore, having a direct engagement with industry, community and government is the cornerstone of achieving effective, efficient and sound success of social innovation [16].

From the above paragraph, whilst the combination of social, economic and technological issues has become critical for all sectors and countries worldwide, Malaysian government have also taken an initiatives in relation to social innovation program with the rest of the world. Social innovation as a new innovation outcome strategy has been addressed in the National Transformational Policy that runs from the period of 2011 until 2020. National Transformational Policy consist of two Malaysian Plan (RMK) which is the 10th Malaysian Plan (RMK-10) from 2011-2015 and also the 11th Malaysian Plan (RMK-11) from 2016-2020, respectively. Under the 10th Malaysian Plan (RMK-10), the Malaysian government introduced two major strategies namely: Government Transformation Plan (GTP) and Economic Transformation Plan (ETP). The GTP and ETP acted as the blueprint guideline for achieving a high income country status by the year 2020. In achieving the above objective, the GTP and ETP outline the main critical areas that need to be addressed. The main areas outline within the GTP and ETP are among others, raising living standards, improved infrastructures and transportation, reduced cost of living, reducing social problems i.e. crime, corruption, poor education system, human capital development, public service delivery, innovation and public-private partnership, reducing poverty and also financial and entrepreneurship aspects. All of the above are initiatives to address the process of improving the well-being of the Malaysians people and to enhance economic growth which reflect the way 'rakyat' is desires and deserves. By fulfilling the aspirations of the 'rakyat', Malaysia as a nation is expecting to have a better GDP growth, to improve business performances, enhance the number of jobs creations, to reduce and eradicate poverty and also to improve the standard of living and well-being of the people.

To elaborate further, The RMK-11 (2016-2020), act as the successor of the previous RMK-10 (20112015).The policies, programs and initiatives that were development under RMK-10 layout the foundation of social innovation that to be included in the master plan of National Transformation Policy. The RMK-11 with the theme of "anchoring growth on people" are the real platform for social innovation to begins with in facilitating Malaysian government to achieve the status of high income country by the year 2020. Social innovation as an outcome of new innovation strategy with hope to propel Malaysia to achieve real GDP percentage of $6 \%$ per annum, Gross national income per capita of USD 15,690.00 which is the threshold of 
Addressing Social Innovation in the Malaysian Knowledge Transfer Program: Gaining a ..

high income country, average monthly household income of USD 2,763.00 and also to increase the quality and quantity of life of the people's index to $1.7 \%$ per annum. Under the RMK-11, social innovation plays the pivotal role as the game changer in creating a new and novel solution that can be embedded into products, processes and services that can serves unmet social needs which in turn leads to improve the well-being of the people and sustained economic growth. This contribution is outline in the RMK-11 strategic thrust. In addition, like many other developing countries, social innovation is done through broader collaboration and partnership between Malaysian private, academic and community institutions. The partnership of university-industry and community involved the creation of superior knowledge resource through the processes of knowledge creation, knowledge transfer and knowledge application among various actors in the Malaysian KTP projects.

Thus, it is important for Malaysian government to have a feedback through scientific research study on how this partnership is progressing and whether the outcome is in line with the main objective enshrines in the RMK-11. Therefore, there is a need to explore social innovation as a new paradigm of innovation outcome strategy within the Malaysian KTP projects and subsequently provide feedbacks and recommendations that add value to the current policies of Malaysian KTP. This is the primary purpose of this paper. This paper is set out in three sections. First, the paper focuses on the selected literature of social innovation and its linkage with knowledge resource. Secondly, review the literature on KTP. Following, the paper outlined the methodology section. Finally, the paper ends by enveloping the conclusion of the thought.

\section{Social Innovation And Knowledge Resource}

The concept of technological innovation by [17] is regards as the pioneer work of innovation concept, whereby the author describes technological innovation as a 'new combination' and 'creative destruction' which refers to the introduction of new quality product, new method of production, new market and new source of financial and also new raw materials. To elaborate further, [18] highlighted, the above tangible elements is regard as the main indicators of innovation to gauge the magnitude of innovation during those economic timeframe [19]. Since the introduction of Schumpeter's technological innovation concept, there have been a growing number of innovation approaches emerged especially in the 1980s and 90s [19]. The most notable are from [20], [21], [22]. Ironically, all of the above scholars are merely focusing on technological and commercial outcome when discussing on innovation concept. However, they extend the basic foundation of Schumpeter's technological innovation concept by highlighting new technological innovation not only can be achieve through tangible resources i.e. raw materials, machinery, monetary, but technological innovation can also be achieve through intangible resource for example human economic behavior which refers to knowledge resource.

After giving the recognition of the profound works of early notable innovation scholars mentioned above, today's modern concept of innovation has considered knowledge resource as the new basis for innovation [23], [24]. Knowledge resource is created through the integrated processes of knowledge creation, knowledge transfer and knowledge application and it involved the interplay of tacit and explicit knowledge [25]. Furthermore, it is embedded into products, processes and services to make them highly innovative and in turn contribute not only towards technological but also towards social and economic benefits [26], [27]. This modern concept of innovation creates a new paradigm of innovation that gives a concurrent benefits within the aspects of social, economic and technology and it provides an outstanding solution to all stakeholders concerned in order to help them overcoming the most crucial and long-standing social and economic problems faced by many nations worldwide [28]. From the previous statements, the literature describes this new paradigm of innovation as social innovation [4] [5]. To explained further, [4] highlighted that the main underlying premise of social innovation is that knowledge resource creates a new solution into creating a highly innovative products, processes and services that simultaneously meets social, economic and technological needs and consequently leads to a new improved capabilities and relationship and better use of assets and resources and enhance quality and quantity of people's life. Specifically, social innovation includes and integrates social, economic and technological approach in order to meet the demands and pressures of new economic environment [3]. With the integration of social, economic and technological approach, there is a collective dynamic interplay that guarantees all stakeholders concerned a considerable return with regards to these three aspects [9].

From the above paragraphs, various empirical studies give evidence to justify the outcomes of social innovation and knowledge resource towards social, economic and technological payoffs. Empirical evidence shows that, social innovation helps to improve societal, economic and technological related problems by creating new knowledge resource which acts as a novel solution into products, processes and services that work to meet pressing social, economic and technological needs and to improve quantity and quality of people's life [4]. An empirical findings by [29] and [4] found that in the aspect of poor public education system, social innovation offers new solutions i.e. superior knowledge resource; that contributes to a better future knowledge worker. [30] also revealed that the result of deployment of superior knowledge resource within social innovation outcome on the issues of massive unemployment, contributes towards increase in employment among people and also increase in consumption of economic benefits. Moreover, [31] and [32] highlighted that social 
innovation with the presence of superior knowledge resource leads to the introduction of superior products, processes and services that have a multiplier effects on the economic value in terms of profit maximization, market share monopoly and enhance private performance. [33], also showed the positive effect of social innovation and knowledge resource on the issues of social health. Knowledge resource leads to the establishment of superior medical products that can improve and enhance people's health. A study by [34] highlighted the positive association between social innovation and knowledge resource in the healthcare industry. Their study shows that new knowledge resource created from university-industry partnership had contribute towards improving quality and quantity of life and enhance people's health. The result of new knowledge resource being applied had reduced the cost of healthcare which means that society can enjoy an affordable medicine. Furthermore, their study shows that knowledge resource and social innovation as an outcome of innovation strategy leads to contribute toward more accessibility of healthcare for all people in the society. In addition, both elements act as a driver of change in healthcare practice which leads to greater public awareness of health risks and benefits. A part from that, the establishment of advance medical products, processes and services have also contribute massively to the industry partners in terms of commercial and private returns that stimulates economic growth [33]. Furthermore, according to [35] [36] and [37], the association of social innovation and knowledge resource creates a superior products, process and services that leads to generating new jobs creation, enhance human capital and skills and also enhance social integrations and formalization for a better quality of working life. Therefore, social innovation is regarded as an important outcome of innovation strategy that provide new and novel solution i.e. knowledge resource; in dealing with social, economic and technological issues and other global issues which are becoming more crucial and requires continuous solutions to cope with [1].

From the above paragraph, empirical evidence clearly shown that social innovation as a new innovation outcome strategy are linked positively with knowledge resource in producing highly innovative products, processes and services that in turn provide a significant benefits on social, economic and commercial aspects to the wider society, private and also for the government in particular [38]. Contrary to technological innovation which is said to have limited offers towards merely fulfilling private needs. With that, the association of social innovation and knowledge resource is immensely important to all nations worldwide as the source of opportunities to developed new ideas and innovation, to solving long-standing social and economic problems and to enhance market needs [39]. The next section explained KTP within the university-industry-community partnership and how knowledge is created within the partnership.

\section{Knowledge Transfer Partnership (KTP)}

Within the literature, knowledge transfer can be defined as the process through which one unit for example an individual, group, department, division or organization is affected by the experience of another [40]. To elaborate further, knowledge transfer involves the process of transmission of knowledge resource from a source to recipient and the knowledge resource is then absorbed and improves the behavior and performance of the knowledge recipient [41]. For [42], knowledge transfer is an activity of exchanging two knowledge resources namely, tacit and explicit knowledge between source and recipient. The knowledge resource is then transmitted, absorbs and applied that leads to changes in behavior and performance of the recipient [43], [44]. According to [45], source and recipient of knowledge transfer process is refers to individual, unit, department and between organization. [46] and [47] identify that knowledge transfer partnership between various organizations is proven to be more central and have a significant impact towards organization in searching for a new knowledge resource. To elaborate further, studies by [48] [49] and [50] highlighted knowledge resource created between organization for example through partnership, collaboration and strategic alliances is appears to be rare, unique, valuable and inimitability which reason out that external source of knowledge resource is more attractive. Furthermore, the difficulty of organization to rely exclusively on in-house creation of knowledge resource due to limited expertise and resources is also one of the main factors as to why organization is seeking partnership with others to create new knowledge resource [51]. This approach is coined by [52] as open innovation. According to [53], open innovation refers to the new knowledge resource gained by a particular organization through partnership or collaboration. In addition, the knowledge resource gained through open innovation benefited organizations to find better sites for their commercialization and also as new offerings and new business models. According to [54] by leveraging external source of knowledge resource, organization is said aimed at the realization of shared benefits and spreading the costs and risks across multiple partners.

From the above paragraphs, [45], highlighted knowledge transfer partnership between universityindustry-community is the central and integral platform for organizations to seek for specialized and superior knowledge resource to be embedded into particular products, processes and services [55]. This is due to the facts that, university is seen as a potential source of new knowledge resource for innovation, economic growth and competitiveness and direct relationships between university-industry-community can bring massive contribution towards the nation as a whole [56]. According to [57], as a key producer of new knowledge resource in today's 
knowledge led economy, universities are now viewed as an economic agent that must engage with multiplicity of stakeholders and also to the larger society in order to deliver social, economic and technological benefits. To elaborate further, [58] describe university-Industry-community partnership is any exchange of knowledge resource i.e. tacit and explicit, between actors in the partnership which aims to enhance the use of research results by industry and community. University-industry-community knowledge transfer partnership involved a wide range of different activities and also interactions mostly aimed for exchanging tacit and explicit knowledge [59]. Among others are network participation, student internship, Research and Development (R\&D), sharing facilities, licensing, patenting and Spin-out company and lectures and exhibitions for the community [60], [61].

Within the partnership activities and interactions, knowledge resource is created through the processes of knowledge creation, knowledge transfer and knowledge application [25]. Knowledge creation is associated with the development of new tacit and explicit knowledge within actors involved, knowledge transfer refers to the actual transmission process whereby tacit and explicit knowledge is transferred between actors involves and knowledge application is describe as to how the new tacit and explicit knowledge is absorb and applied into products, processes and services by actors involved to create value and high innovation which in turn could contribute towards social, economic and technological aspects [62], [25]. Figure 1.0 illustrates the conceptual view of strategic knowledge management processes and social innovation.

Figure 1.0: Conceptual view of strategic knowledge management processes and social innovation

[University-Industry-Community KTP partnership]

[University-Industry-Community KTP partnership]

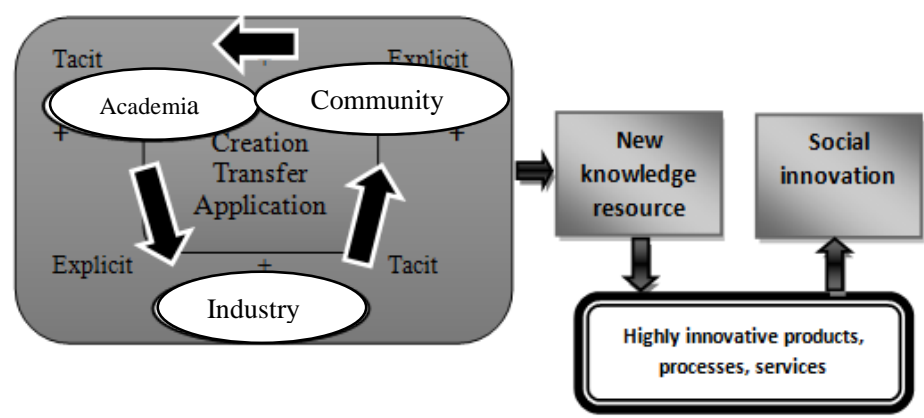

Figure 1.0 provides the illustration of how new knowledge resource is created within universityindustry-community partnership. Within the partnership, all actors consists of academia, business owner and community actor exchanging of different tacit and explicit knowledge within the processes of knowledge creation, knowledge transfer and knowledge application. Moreover, the dynamic jointly sharing and exchanging of tacit and explicit knowledge within the aforementioned processes develops a superior, rare, unique, valuable and inimitability new knowledge resource that can be embedded into products, processes and services and contributes towards social innovation (social, economic and technological benefits).

In tandem with the subsequent conceptual view in figure 1.0 of the preceding paragraph, this study would like to observe how the dynamic of strategic knowledge management processes and social innovation interplay amongst it actors in the university-industry-community KTP partnership ecosystem in Malaysia in light of producing new knowledge resource.

\subsection{Research Setting}

\section{Methodology}

Research setting is described as the detailed plan for a study that includes of samples, data collection method, data analysis and the findings [63]. According to [64], research setting is a master plan and procedures of how researcher will go about in answering the questions under investigation that have been set earlier. This paper used a qualitative approach of inquiry in order to explore social innovation as a new paradigm of innovation outcome strategy within the Malaysian KTP projects. The choice of qualitative approach of inquiry is made considering the aims of this paper is to address social innovation in the Malaysian knowledge transfer program and to gain some preliminary insight of social innovation as a new innovation outcome strategy and its association with knowledge resource in the Malaysian KTP projects. The qualitative approach of inquiry will helps researchers to have a better understanding of belief, perception and experiences of individuals towards particular research problems or issues [65] and [64]. According to [66], individual construe the world in different ways. This is in line with the objective of this paper which aims to explore social innovation and knowledge resource by observing the dynamic of strategic knowledge management processes and social innovation interplay amongst it actors in the university-industry-community KTP partnership ecosystem in Malaysia in light of producing new knowledge resource by interpreting it from their view point. The unit of 
analysis of this study is the projects in the Malaysian KTP. Thus, the actors involve in the Malaysian KTP projects is the respondent of this study. This study used semi-structured interview as the medium in collecting a meaningful interpretative insight from the respondents under investigation [66].

\subsection{Data Collection}

Data collection is done through semi-structured interviews. This involves face to face interview sessions with the actors representing academia, industry and community from University A, University B, University C, and University D projects from 1st rolling plan to 5th rolling plan (2011-2015). According to [67], judgment sampling can be defined as respondents or samples that are in the best position to provide with information that requires by researchers. Furthermore, judgment sampling is a group of experts with superior knowledge and information towards a particular issues or subject [68], [64]. Thus, selecting the academia as project leaders, industry actors and community actors to participate in the interview sessions is justified based on the fact that they are the experts group that has the superior knowledge, experience and information within the partnership that are required in answering the objective of tis paper. Based on the simple rules of thumb of qualitative approach of inquiry, at least 12 interview sessions have to be conducted in order to ensure the adequate richness of qualitative data approach [66], [69], [70]. Thus, 12 interview sessions that consist of 8 KTP projects are conducted in order to explore dynamic of strategic knowledge management processes and social innovation interplay amongst it actors in the university-industry-community KTP partnership ecosystem in Malaysia. The preliminary interview sessions and repeated interviews sessions is done in May 2016 until September 2016 and the duration of each interview is about 2 hours long.

\subsection{KTP Projects Samples}

This paper chooses twelve (12) actors to become the interviewee within the Malaysian KTP projects that consist of four (4) project leaders (university actors), four (4) CEO/ Owner/ member of company (industry actors) and four (4) Community members (community actors).

\subsection{Data Analysis and Results}

Semi-structured questionnaires were asked during the interview sessions in order to probe specific themes and to gain an insight of each respondent's particular understanding, interpretation, knowledge and experience [71], [64]. The information gathered from semi-structured interview sessions with various actors tabulated and summarize according to the theme. The respondents were asked about the knowledge resource created within the KTP projects and what is the benefits and contribution of their KTP projects outcome. This question were asked in order to probe and to investigate their understanding on social innovation as a new innovation outcome strategy with new knowledge resource created within their KTP projects. The respondents also were asked about their motivation to get involves in the Malaysian KTP project. This question was asked in order to probe and investigate their objectives, interest and priorities towards their involvement in the Malaysian KTP projects. Finally, the respondents were asked on the main problems and challenges with regards to the commercialization activities. This question was asked in order to probe and investigates the main problems faced by various actors involves in the Malaysian KTP projects towards achieving social innovation. The following are the insight from the analysis:

\subsubsection{Social Innovation and Knowledge Resource}

The interviewees were asked on the knowledge resource created within their KTP projects and the contribution and benefits of their KTP projects outcome. All the interviewees that consist of academia, industry and community of University A,B,C and D KTP projects agreed that their KTP project outcome creates new knowledge i.e. new solution, techniques and methods, which can be embedded into products, processes and services or improved existing products, processes and services. When probed further on the contribution and benefits of their KTP projects, preliminary finding shows that, all interviewees very much focus and incline their perception and beliefs towards technological innovation outcome. This situation arises due to the nature and arrangement of the projects that are emphasizes only on solving industries issues and problems. Moreover, for community actors it is appeared the majority of them understand KTP projects as volunteering activities and charitable contribution towards fulfilling the obligation of social responsibility and social connection to the community. Subsequently, almost all interviewed respondents are somewhat not aware and well exposed to the concept and terminology of social innovation as a new outcome of innovation strategy within their KTP projects outcome. Only one academic actor from University A stated: "Our highly innovative product (dermatological product) created through this KTP partnership contributes towards improving health condition among people and at the same time gives benefits towards technological and commercial driven profits. Thus, it gives overall advantage and not only benefited private aspect but also improved social well-being and enhances economic growth in a concurrent way". 


\subsubsection{Objectives, Interest and Priorities}

The interviewees revealed their obvious differences when asked about their motivation to get involved in the Malaysian KTP projects. For academia, it is appeared that their overall objective, interest and priorities to get involved in the KTP projects are mainly due to the funding opportunities for future research, creates future research networking and also focusing on the provision of knowledge and training. Furthermore, the majority of the academia interviewees were in agreement that they interested and focus more on long-term KTP partnership, so that they can establish a successful long-term people based activities and problem solving activities. For industry actors, they highlighted that their primary motive is to gain financial profit, to introduce a new product line, to maintain control over market, to overcome market saturation and also to secure competitive advantage over competitors. All of the industry actor's interviewees appeared to show that their interest and priorities to get involved in the KTP projects merely to pursue private benefits. To elaborate further, majority of them highlighted that they cannot afford to get involved and contribute their time, money and other resources through a long-term KTP partnership without having a short-term commercial return for their involvement and contribution. Moreover, they insist that they have a limitation in terms of financial and human resources in order to become ever ready in every aspect with regards to the KTP projects commitments and duration. For community actors, the majority of the interviewees appeared to show that, their involvement in the KTP projects only to fulfil social responsibility. To explain further, the preliminary finding shows that, almost all community actors highlighted that the KTP project outcomes does not include private aspects but merely to satisfy pure social aspects. As a result, their motivation of getting involves in the KTP projects merely as volunteering activities and charitable contribution towards fulfilling the obligation of social responsibility and social connection to the community. This situation creates an under-investment for KTP projects with the aims to addressing social innovation as a new innovation outcome strategy through knowledge resource created in the KTP projects that might be brought forward to gives significant benefits towards social, economic and technological aspects. According [72], actors in KTP partnership resemble heterogeneous pools of actors, each with their own characteristics, purposes and structures and this can often lead to conflicting objectives, interest, priorities and agendas when having collaboration.

\subsubsection{Main Problems Faced By Various Actors in the Malaysian KTP Projects}

A number of problems and challenges had been identified by all actors when asked on their perception on what are the problems faced in the KTP projects. The problems among others are the presence of high bureaucracy practices, business disclosures issues, innovation requirements issues, understanding and commitment issues and financial constraints issues. However, the main reoccurring problems which appeared to be a cause of concern for all interviewees was the presence of high bureaucracy practices, understanding KTP projects outcome and commitments issues and financial constraints that may affect the success of KTP projects outcome.

\section{Conclusion}

In achieving social innovation as a new innovation outcome strategy and to fulfill the government aspiration highlighted in the Eleventh Malaysian Plan (2016-2020), the Malaysian KTP partnership should adopt the model of Quadruple Helix. Within this model, knowledge based innovation processes consists of four actors within a specific partnership project namely; university, industry, government and public/ civil society. Quadruple helix model is a broad based innovation concept that relates strategic knowledge management activities with not only in the aspect of commercial and economic value but also in the aspect of new social innovation that gives wider societal benefits i.e. improves quality and quantity of people's life which are in line with the Eleventh Malaysian Plan. This can be seen through its structures and processes which encompass university, industry government and public/ civil society actors that make up a specific KTP project. Every actor plays a dependent role within each other's and also involves interactive innovation networks and knowledge clusters in making sure that social innovation is achieved. A better understanding on social innovation as a new innovation outcome strategy must be internalized and institutionalized by all actors involved in the Malaysian KTP projects. Moreover there is an urgent need of synchronization of the objectives, interest and priorities of the actors involves, so that differences in norms, standards and values and also primary mission and objectives can be overcome. Factors such as high bureaucracy practices, business disclosures issues, innovation requirements issues, understanding KTP project outcome and commitment issues and also financial constraints issues must be taken into consideration for improvements and to added value towards the existing policy and procedures. Therefore, with some preliminary insight on addressing social innovation in the KTP projects provided by this paper, it is hope that all stakeholders concerned could have at least some indications on the level of understanding of social innovation as a new innovation outcome strategy in the Malaysian KTP projects. 


\section{Acknowledgements}

The authors would like to thank the anonymous reviewers. The authors would also like to give special thanks to the Knowledge Transfer Program (KTP) secretariat for the funding received under the KTP special research program titled KTP Problem Statements of Industry/ Community Problems in Malaysia and ASEAN Region, SO code 13319.

\section{References}

[1]. Krlev, G., Bund, E., \& Mildenberger, G. (2014). Measuring what matters-Indicators of social innovativeness on the national level. Information Systems Management, 31(3), 200-224.

[2]. Doherty, B., Haugh, H., \& Lyon, F. (2014). Social enterprises as hybrid organizations: A review and research agenda. International Journal of Management Reviews, 16(4), 417-436.

[3]. Makimattila, M., Junell, T., \& Rantala, T. (2015). Developing collaboration structures for university-industry interaction and innovations. European Journal of Innovation Management, 18(4), 451-470.

[4]. Lizuka, M. (2013). Innovation systems framework: still useful in the new global context?. UNU-MERIT. Working paper series United Nations. Maastricht, The Netherlands Innovation, 005

[5]. Kanter, R.M. (2015). From spare change to real change: The social sector as beta site for business innovation. Harvard Business Review, Vol. 77 No. 3, pp. 122-132.

[6]. Pue, K., Vandergeest, C., \& Breznitz, D. (2015). Toward a Theory of Social Innovation. Innovation Policy Lab White Paper, (201601).

[7]. Caulier-Grice, J., Davies, A., Patrick, R., \& Norman, W. (2012). Defining social innovation. A deliverable of the project: The theoretical, empirical and policy foundations for building social innovation in Europe (TEPSIE). European Commission-7th Framework Programme, Brussels: European Commission, DG Research.

[8]. Lee, E. W., \& Restrepo, J. M. (2015). Institutional embeddedness and the scaling-up of collaboration and social innovation: the case of a Hong Kong-based international NGO. Policy \& Politics, 43(3), 459-471.

[9]. Altuna, N., Contri, A. M., Dell Era, C., Frattini, F., \& Maccarrone, P. (2015). Managing social innovation in for-profit organizations: the case of Intesa Sanpaolo. European Journal of Innovation Management, 18(2), 258-280.

[10]. Shaw, E., \& De Bruin, A. (2013). Reconsidering capitalism: the promise of social innovation and social entrepreneurship?. International Small Business Journal, 31(7), 737-746.

[11]. European Commision (2014). Social Innovation - Adecade of changes. BEPA Report. Luxembourg.

[12]. Westley, F., Antadze, N., Riddell, D. J., Robinson, K., \& Geobey, S. (2014). Five Configurations for Scaling Up Social Innovation Case Examples of Nonprofit Organizations From Canada. The Journal of Applied Behavioral Science, 0021886314532945.

[13]. European Commision (2014). Workplace Innovation Concepts and indicators report. Brussels. Belgium.

[14]. Ruede, D., \& Lurtz, K. (2012). Mapping the various meanings of social innovation: Towards a differentiated understanding of an emerging concept. EBS Business School Research Paper, (12-03).

[15]. Stam, E., \& Martin, R. (2011). When high tech ceases to be high growth: The loss of dynamism of the Cambridgeshire region. In Paper presented at the DIME Final Conference, April. (Vol. 6, p. 8).

[16]. Benneworth, P., \& Cunha, J. (2015). Universities contributions to social innovation: reflections in theory \& practice. European journal of innovation management, 18(4), 508-527.

[17]. Schumpeter, J. A. (1947). The creative response in economic history. The journal of economic history, 7(02), 149-159.

[18]. Dodgson, M. (2011). Exploring new combinations in innovation and entrepreneurship: social networks, Schumpeter, and the case of Josiah Wedgwood (1730-1795). Industrial and Corporate Change, 20(4), 1119-1151.

[19]. Nicholls, A., \& Murdock, A. (2012). The nature of social innovation. In Social innovation (pp. 1-30). Palgrave Macmillan UK.

[20]. Nelson, R. R., \& Winter, S. G. (1982). An Evolutionary Theory of Economic Change. Harvard University Press,Cambridge, Massachusetts.

[21]. Freeman, C. (1982). Innovation and long cycles of economic development. Seminario Internacional. Universidade Estadual de Campinas, Campinas, 1-13.

[22]. Rothwell, R. (1992). Successful industrial innovation: critical factors for the 1990s. R\&D Management, 22(3), 221-240.

[23]. Alegre, J., \& Chiva, R. (2008). Assessing the impact of organizational learning capability on product innovation performance: An empirical test. Technovation, 28(6), 315-326.

[24]. Sammarra, A., \& Biggiero, L. (2008). Heterogeneity and specificity of Inter-Firm knowledge flows in innovation networks. Journal of Management Studies, 45(4), 800-829.

[25]. Meier, M. (2011). Knowledge management in strategic alliances: A review of empirical evidence. International Journal of Management Reviews, 13(1), 1-23.

[26]. Lichtenthaler, U., \& Lichtenthaler, E. (2009). A capability-based framework for open innovation: Complementing absorptive capacity. Journal of Management Studies, 46(8), 1315-1338.

[27]. Chiva, R., Ghauri, P., \& Alegre, J. (2014). Organizational learning, innovation and internationalization: A complex system model. British Journal of Management, 25(4), 687-705.

[28]. Moore, M. L., Westley, F. R., \& Brodhead, T. (2012). Social finance intermediaries and social innovation. Journal of Social Entrepreneurship, 3(2), 184-205

[29]. Surikova, S., Oganisjana, K., \& Grinberga-Zalite, G. (2015, May). The Role of Education in Promoting Social Innovation Processes in the Society. In SOCIETY, INTEGRATION, EDUCATION. Proceedings of the International Scientific Conference (Vol. 4, pp. 233-243).

[30]. Scheuerle, T., Schmitz, B., Spiess-Knafl, W., Schues, R., \& Richter, S. (2015). Mapping social entrepreneurship in Germany-a quantitative analysis. International Journal of Social Entrepreneurship and Innovation, 3(6), 484-511.

[31]. Cajaiba-Santana, G. (2014). Social innovation: Moving the field forward. A conceptual framework. Technological Forecasting and Social Change, 82, 42-51. [30] Scheuerle, T., Schmitz, B., Spiess-Knafl, W., Schues, R., \& Richter, S. (2015).

[32]. Spiess-Knafl, W., Mast, C., \& Jansen, S. A. (2015). On the nature of social business model innovation. Social Business, 5(2), 113130.

[33]. El Arifeen, S., Christou, A., Reichenbach, L., Osman, F. A., Azad, K., Islam, K. S., \& Peters, D. H. (2013). Community-based approaches and partnerships: innovations in health-service delivery in Bangladesh. The Lancet, 382(9909), 2012-2026.

[34]. Pratt, B., \& Loff, B. (2012). Health research systems: promoting health equity or economic competitiveness?. Bulletin of the World Health Organization, 90(1), 55-62. 
[35]. Howlett, R. J. (2010). Knowledge transfer between UK universities and business. In Innovation through Knowledge Transfer (pp. 114). Springer Berlin Heidelberg.

[36]. Hurmelinna-Laukkanen, P., Olander, H., Blomqvist, K., \& Panfilii, V. (2012). Orchestrating R\&D networks: Absorptive capacity, network stability, and innovation appropriability. European Management Journal, 30(6), 552-563.

[37]. Cepeda-Carrion, G., Cegarra-Navarro, J. G., \& Jimenez-Jimenez, D. (2012). The effect of absorptive capacity on innovativeness: Context and information systems capability as catalysts. British Journal of Management, 23(1), 110-129.

[38]. Miller, K., McAdam, R., Moffett, S., Alexander, A., \& Puthusserry, P. (2016). Knowledge transfer in university quadruple helix ecosystems: an absorptive capacity perspective. R\&D Management.

[39]. Du, S., Swaen, V., Lindgreen, A., \& Sen, S. (2013). The roles of leadership styles in corporate social responsibility. Journal of business ethics, 114(1), 155-169.

[40]. Argote, L., \& Ingram, P. (2000). Knowledge transfer: A basis for competitive advantage in firms. Organizational behavior and human decision processes, 82(1), 150-169.

[41]. Szulanski, G., Cappetta, R., \& Jensen, R. J. (2004). When and how trustworthiness matters: Knowledge transfer and the moderating effect of causal ambiguity. Organization Science, 15(5), 600-613.

[42]. Kumar, A.J., \& Ganesh, L. S. (2009). Research on knowledge transfer in organizations: a morphology. Journal of Knowledge Management, 13(4), 161-174.

[43]. Steensma, H. K., \& Lyles, M. A. (2000). Explaining IJV survival in a transitional economy through social exchange and knowledge-based perspectives. Strategic Management Journal, 21(8), 831-851.

[44]. Liyanage, C., Elhag, T., Ballal, T., \& Li, Q. (2009). Knowledge communication and translation-a knowledge transfer model. Journal of Knowledge management, 13(3), 118-131.

[45]. Easterby-Smith, M., Lyles, M.A., \& Tsang, E.W. (2008). Inter-organizational knowledge transfer: Current themes and future prospects. Journal of Management Studies, 45(4), 677-690.

[46]. Van Wijk, R., Jansen, J.J., \& Lyles, M.A. (2008). Inter-and Intra-Organizational Knowledge Transfer: A Meta-Analytic Review and Assessment of its Antecedents and Consequences. Journal of Management Studies, 45(4), 830-853.

[47]. Audretsch, D., Hulsbeck, M., \& Lehmann, E. E. (2012). Regional competitiveness, university spillovers, and entrepreneurial activity. Small Business Economics, 39(3), 587-601.

[48]. Menon, T., \& Pfeffer, J. (2003). Valuing internal vs. external knowledge: Explaining the preference for outsiders. Management Science, 49(4), 497-513.

[49]. Perez-Nordtvedt, L., Kedia, B. L., Datta, D. K., \& Rasheed, A. A. (2008). Effectiveness and efficiency of cross-border knowledge transfer: An empirical examination. Journal of Management Studies, 45(4), 714-744.

[50]. Becerra, M., Lunnan, R. and Huemer, L. (2008). Trustworthiness, risk, and the transfer of tacit and explicit knowledge between alliance partners. Journal of Management Studies, 45, 691-713.

[51]. Contractor, F. J., \& Lorange, P. (Eds.). (2002). Cooperative strategies and alliances. Boston, MA: Elsevier Science.

[52]. Chesbrough, H.W. (2003). Open innovation: The new imperative for creating and profiting from technology. Harvard Business Press.

[53]. Chesbrough, H., \& Crowther, A. K. (2006). Beyond high tech: early adopters of open innovation in other industries. R\&d Management, 36(3), 229-236.

[54]. Huggins, R. (2010). Forms of Network Resource: Knowledge Access and the Role of Inter-Firm Networks. International Journal of Management Reviews, 12(3), 335-352.

[55]. Wang, Z., \& Wang, N. (2012). Knowledge sharing, innovation and firm performance. Expert systems with applications, 39(10), 8899-8908.

[56]. Breznitz, S. M., \& Ram, N. (2013). Enhancing economic growth? University technology commercialization. Creating Competitiveness: Entrepreneurship and Innovation Policies for Growth: Edward Elgar Publishing, 88-115.

[57]. Robertson, S., \& Kitagawa, F. (2011). University Incubators and Knowledge Mediation Strategies: Policy and Practice in Creating Competitive City-Regions. LLAKES Research Paper, 28.

[58]. King, W. R. (2007). A research agenda for the relationships between culture and knowledge management. Knowledge and process management, 14(3), 226-236.

[59]. Rossi, F. (2010). The governance of university-industry knowledge transfer. European Journal of Innovation Management, 13(2), $155-171$.

[60]. Abreu, M., Grinevich, V., Hughes, A., \& Kitson, M. (2009). Knowledge exchange between academics and the business, public and third sectors. UK-Innovation Research Centre.

[61]. Cosh, A., \& Hughes, A. (2010). Never mind the quality feel the width: University-industry links and government financial support for innovation in small high-technology businesses in the UK and the USA. The Journal of Technology Transfer, 35(1), 66-91.

[62]. Jiang, X., \& Li, Y. (2009). An empirical investigation of knowledge management and innovative performance: The case of alliances. Research Policy, 38(2), 358-368.

[63]. Kumar, M., Talib, S. A., \& Ramayah, T. (2013). Business research methods. Oxford Fajar/Oxford University Press.

[64]. Saunders, M., Lewis, P. \& Thornhill, A. (2007). Research methods for business students, 4th edition. Harlow: Prentice Hall.

[65]. Creswell, J. W. (2003). Research Design: Qualitative. Quantitative and Mixed Methods Approaches, 2nd Edition. London, UK: Sage Publications.

[66]. Creswell, J. W. (2013). Research design: Qualitative, quantitative, and mixed methods approaches. Sage publications.

[67]. Hair, J. F., Ringle, C. M., \& Sarstedt, M. (2011). PLS-SEM: Indeed a silver bullet. Journal of Marketing theory and Practice, 19(2), $139-152$.

[68]. Zikmund, W.G. (2000). Business Research Methods (6th ed.). Orlando, US: Dryden Press.

[69]. Guest, G., Bunce, A., \& Johnson, L. (2006). How many interviews are enough? An experiment with data saturation and variability. Field methods, 18(1), 59-82.

[70]. Yin, R.K. (2009). Case study research: Design and Methods, 4th edition. California: Sage Publication.

[71]. Jordan, F., \& Gibson, H. (2004). Let your data do the talking. In Phillimore,J. \& Goodson, L. (Eds). Qualitative research in tourism: London : Routledge, pp. 215-235.

[72]. Bramwell, A., Hepburn, N., \& Wolfe, D. A. (2012). Growing innovation ecosystems: University-industry knowledge transfer and regional economic development in Canada. Knowledge Synthesis Paper on Leveraging Investments in HERD. Final Report to the Social Sciences and Humanities Research Council of Canada. 